детей / Т. Зуева // Проблемы интерпретации художественных произведений. - М., 1985. - C. 147-148.

Ковтун E.H. Поэтика необычайного: Художественные миры фантастики, волшебной сказки, утопии, притчи и мифа (На материале европейской литературы первой половины XX века) / Е.Н. Ковтун - М. : Изд-во МГУ, 1999. - 308 с.

Мелетинский E.M. Миф и сказка / Е.М. Мелетинский // Мелетинский Е.М. Избранные статьи. Воспоминания. - М., 1970. - С. 284-296.

Пропn В.Я. Исторические корни волшебной сказки / В.Я. Пропп. - Л. : Изд-во ЛГУ, 1986. $-364 \mathrm{c}$.

Celtic Fairy Tales / ed. J. Jacobs. - London : D. Nutt, 1892. - 267 pp.

English Fairy Tales / ed. J. Jacobs. - London : D. Nutt, 1890. - 253 pp.

Harper D. Online Etymology Dictionary 2001-2012 / Douglas Harper [electronic resource]. - Режим доступа: http://www.etymonline.com/index.php (дата обращения: 21.11.2012).

More Celtic Fairy Tales / ed. J. Jacobs. - London : D. Nutt, 1894b. - 234 pp.

More English Fairy Tales / ed. J. Jacobs. - London : D. Nutt, 1894a. - 243 pp.

\title{
СЛЕНГ ГЕЙМЕРОВ
}

А.М. Зияитдинов

Научный руководитель: А.А. Шагеева, кандидат филологических наук, дочент (УрФУ)

Понятие сленга все больше начинает завоевывать внимание современной филологии и является актуальным вопросом последней, чем объясняется выбор сленга в качестве объекта нашего исследования. Изучение сленга невозможно без уточнения его определения, а также отграничения данного понятия от близких ему понятий.

В настоящее время существует достаточно большое количество определений сленга, нередко противоречащих друг другу. Противоречия эти касаются прежде всего объема понятия «сленг»: спор идет, в частности, о том, включать ли в сленг одни лишь выразительные, ироничные слова, которые являются синонимами литературных эквивалентов, или же еще и всю нестандартную лексику.

Дать определение сленгу пытались многие ученые, как отечественные (В.А. Хомяков, О.С. Ахманова, И.Р. Гальперин и др.), так и зарубежные (Ч. Фриз, Эрик Партридж, Р. Спирс и др.). Однако можно констатировать, что, при всей его популярности, в настоящее время ученые еще не полностью сошлись в мнении относительно точного определения сленга.

Согласно Н.О. Орловой, можно выделить несколько наиболее существенных свойств сленга.

1. Сленг - это нелитературная лексика, т.е. слова и сочетания, находящиеся за пределами литературного языка - с точки зрения требований современной литературной нормы. 
2. Сленг - это лексика, возникающая и употребляющаяся, прежде всего, в устной речи.

3. Сленг - это эмоционально окрашенная лексика.

4. Сленг характеризуется более или менее ярко выраженной фамильярной окраской подавляющего большинства слов и словосочетаний. Это свойство сленга ограничивает стилистические границы его употребления.

5. Фамильярная эмоциональная окраска многих слов и выражений сленга отличается большим разнообразием оттенков (шутливая, ироническая, насмешливая, пренебрежительная, презрительная, грубая и даже вульгарная).

6. Многие слова и выражения сленга непонятны или малопонятны для основной массы населения (особенно в период их возникновения и перехода в более широкую сферу употребления), потому что они прежде всего связаны со своеобразной формой выражения - например, при многочисленных случаях переноса значения (фигурального употребления), столь характерного для сленга. Непонятность может также быть результатом того, что эти сленгизмы представляют собой заимствования из диалектов и жаргонов иностранных языков.

7. Сленг включает в себя различные слова и словосочетания, с помощью которых люди могут отождествлять себя с определенными социальными и профессиональными группами.

8. Сленг - это яркий, экспрессивный слой нелитературной лексики, стиль языка, который занимает место, прямо противоположное крайне заформализованной речи. Сленг - это живой, подвижный язык, который идет в ногу со временем и реагирует на любые перемены в жизни страны и общества [Орлова 2004: 5].

Существует несколько классификаций сленга. Например, можно делить сленг по языку, в котором он представлен. Тогда мы получим британский, американский, русский, австралийский и т.д. виды сленга. Почти в каждом языке будет присутствовать слой лексики, называемый сленгом.

Можно классифицировать сленг и по сфере употребления. В этом случае выделяются такие виды сленга, как молодежный [Борисова 1980: 51-54], военный [Судзиловский 1973: 23], компьютерный [Лихолитов 1997: 43-49].

В нашем случае особый интерес представляет компьютерный сленг.

В настоящее время во всем мире развитию компьютерных технологий уделяется огромное внимание. В связи с этим первой по количеству появляющихся новых слов является именно область компьютерных 
технологий.

Но в чем же отличие компьютерного сленга от тех же профессионализмов, жаргонизмов и вульгаризмов? В. Рюгемер считает, что, имея дело с компьютерным сленгом, мы имеем дело с некоторым синтезом всех трех видов нелитературной лексики.

Во-первых, эти слова служат для общения людей одной профессии программистов, или просто людей, использующих компьютер для какихто целей. При этом сленговые слова используются в качестве синонимов к английским профессиональным терминам, отличаясь от них эмоциональной окраской.

Во-вторых, компьютерный английский сленг отличается «зацикленностью» на реалиях мира компьютеров.

И, в-третьих, в числе этой лексики нередки и достаточно вульгарные слова: групповуха под Винды 'Windows for WorkGroup', анус 'протокол Janus', блястер 'Sound Blaster' и т.п.

Таким образом, эти три наблюдения не позволяют причислить компьютерный сленг ни к одной отдельно взятой группе нелитературных слов и заставляют рассматривать его как явление, которому присущи черты каждой из них. Это и позволяет определить термин «компьютерный сленг» как слова, употребляющиеся только людьми, имеющими непосредственное отношение к компьютерам в повседневной жизни, заменяющие профессиональную лексику и отличающиеся разговорной, а иногда и грубо-фамильярной окраской.

Кроме того, нельзя забывать, что большинство слов, относящихся к компьютерному сленгу, являются производными от профессиональных терминов, практически все из которых заимствованы из английского языка [Рюгемер 1989: 31].

Таким образом, рассмотрев различные аспекты сленга, мы пришли к выводу, что единого мнения насчет места сленга в системе языка еще нет, и он изучен не в полной мере. Что касается компьютерного сленга и игрового в частности, здесь ситуация еще сложнее, так как персональные компьютеры получили широкое распространение сравнительно недавно, а язык его пользователей не устоялся и вряд ли когда-нибудь устоится, потому что развитие технологий идет очень быстрыми темпами и вследствие этого всегда присутствует необходимость описания новых явлений.

Среди проблем изучения сленга в современной лингвистике можно выделить: неточное определение понятия «сленг»; разногласия насчет числа пластов лексики, охватываемых данным понятием; особенности видов сленга; их классификация. Теперь мы попытаемся выделить основные особенности сленга геймеров и разработать его классификацию. 
Игровой сленг ввиду своей специфической сферы применения (в процессе игры) обладает рядом особенностей.

Сначала следует сказать о такой характеристике сленга, как краткость. Действительно, если рассмотреть примеры игрового сленга, то мы заметим, что большое количество слов состоит из одного, двух, максимум трех слогов: burst 'attack dealing maximum damage in a short period of time', NPC 'non-player character, a character controlled by computer', boss 'NPC difficult to kill', mob 'NPC not very difficult to kill in comparison with boss'. Данная особенность является следствием того, что зачастую в игре победу или поражение определяют несколько секунд и быстрый обмен информацией является задачей первостепенной важности. Приведем в качестве примера такое предложение: First focus adds, then boss. At $10 \% \mathrm{hp}$ burst. Slackers will be kicked. Если пытаться выразить данное предложение средствами литературного языка, то получится примерно следующее высказывание: First attack only additional monster, then main monster. When he has $10 \%$ hit points, do as maximum damage as you can in a short period of time. Those who will play badly and won't attack will be excluded from the group. Как мы видим, увеличение в объеме сообщения значительно, в то время как смысл остался тот же. Порой команды, профессионально занимающиеся киберспортом, по сути дела, официально устраиваемыми соревнованиями по компьютерным играм, где на кону могут быть тысячи долларов, разрабатывают свою собственную систему условных названий мест, предметов или приказов (иногда эти названия могут быть такими краткими и удобными, что и остальные люди начинают ими пользоваться).

Игровой сленг также очень эмоционален. Особенно это проявляется при оценке уровня игры того или иного человека. Если вы играете плохо, вас могут назвать целым рядом обидных выражений: noob, newbie (от new beginner), которое имеет как негативный, так и снисходительный характер, slacker, является крайне негативным названием. Если же хорошо, то pro (professional), одобрительная коннотация, imba (imbalanced), обычно с досадой, одобрением, также может применяться и к другим игровым элементам (игровым предметам, навыкам). Причиной эмоциональности игрового сленга служит то, что часто во время игры страсти накаляются до предела, и человеку приходится каким-либо образом выразить эмоции. Так что порой человека могут заслуженно и незаслуженно называть негативными словами. Кстати, именно по причине высокой напряженности при игре люди часто используют нецензурную лексику, так как именно она является самой эмоциональной среди всех пластов лексики языка.

Таким образом, мы определили особенности сленга геймеров. Это 
краткость и взаимосвязанная с ним содержательность и эмоциональность. Мы определили основные причины данных особенностей: необходимость быстрой передачи информации и эмоциональная напряженность игры. Теперь перейдем к следующей задаче нашей работы: классификации игрового сленга.

П.А. Горшков в своей работе «Сленг хакеров и геймеров в интернете» подразделяет игровой сленг на две категории: сленг устный и используемый в процессе переписки в чате [Горшков 2006: 112]. Она основывается на идее, что «чатовый» сленг является более кратким, что в нем используется больше аббревиатур и сокращений, в то время как при устном общении используются более полные конструкции. Однако мы считаем, что данная классификация приемлема не в полной мере, так как здесь внимание уделяется не столько сленгу, сколько предпочтению в выборе более удобных для передачи информации слов и конструкций. Мы же попытаемся классифицировать сам сленг, то есть его лексическую составляющую.

Для этого нам необходимо выделить два или больше членов, один из которых будет маркированным, а другой или другие - нет.

Мы предлагаем выделить два члена. Первый - это часть игрового сленга, относящаяся к социальной стороне игры, то есть к общению. Сюда входят различные оценочные названия игроков (pro, imba, noob), слова ободрения, поддержки (gg - good game, gj - good job, gz - gratz, congratulations), также сюда можно отнести заимствования из интернетсленга (lol - laughing out loud, OMG - oh my god). Данный элемент является маркированным. Оставшуюся часть игрового сленга будут составлять слова, непосредственно относящиеся к игровому процессу, названию явлений и предметов игры (boss, tank, dd - damage dealer, location, DPS - damage per second). Назовем данный немаркированный член предметно-процессуальным.

Таким образом, мы имеем две категории игрового сленга: социальную и предметно-процессуальную. Следует отметить, что для первой категории более характерна эмоциональность, так как в процессе общения люди выражают свои эмоции и свое отношение (к игре, к людям и т.д.), а для второй - краткость, так как названия предметов и явлений в игре часто слишком длинные и сложные для произношения (BG-battleground).

Кроме того, существует идея классифицировать игровой сленг согласно игре, в которой он встречается. Данное предложение является вполне оправданным, так как существует множество различных игр, игроки которых используют сленговые понятия, характерные только для конкретной игры. В основном это названия «географических» мест на игровой карте (WG - warsong gulch, специальная карта для сражения в 
игре World of warcraft). Однако при этом придется выделить в отдельную категорию слова, встречающиеся в большинстве игр. К данной категории будут относиться слова, обозначающие процессы или явления, характерные для определенных жанров игр. Например, в большинстве игр жанра MMORPG (massive multiplayer online role-playing game) будут характерны такие сленгизмы, как stats, skills, ability, так как они являются названиями параметров и способностей, которыми может обладать виртуальный персонаж. Сравните с headshot - убийство выстрелом в голову, выражение используемое в сетевых «стрелялках». В играх жанра MMORPG действия обычно происходят в фэнтезийных мирах, где нет даже огнестрельного оружия, так что не будет таких ситуаций, где можно употребить данное выражение.

Мы выяснили, что сленг обладает особыми, характерными для него свойствами. Он является кратким и, что самое важное, емким. Лексика, присутствующая в нем, является очень содержательной. Как мы уже говорили, это обусловлено задачами большинства игр, где нужно быстро передавать необходимую информацию или приказы. Другой особенностью сленга является его эмоциональность, возникающая вследствие эмоционального напряжения геймеров.

Кроме того, мы классифицировали сленг геймеров по двум категориям: социальная и предметно-процессуальная. Как выяснилось, данные категории корреспондируют с особенностями сленга геймеров. Так, социальная лексика игрового сленга оказалась более эмоциональной, в то время как предметно-процессуальная - более содержательной.

Следует отметить, что данная статья, носящая главным образом обзорный характер, - это только часть исследования компьютерного сленга с различных позиций: его формальных характеристик, классификации, функционирования в русском и английском языках, вопросов перевода сленга и т.д.

\section{Список литературы}

Борисова Е.Г. Современный молодежный жаргон / Е.Г. Борисова // Русская речь. - 1980. - № 5. - C. 51-54.

Горшков П.А. Сленг хакеров и геймеров в Интернете : автореф. дис. ... канд. филол. наук / П.А. Горшков ; Мос. гос. обл. ун-т. - М.: [б.и.], 2006. - 150 с.

Лихолитов П.В. Компьютерный жаргон / П.В. Лихолитов // Русская речь. - 1997. - № 3. - C. 43-49.

Орлова Н.О. Сленг vs жаргон: проблема дефиниции / Н.О. Орлова // Ярославский педагогический вестник. - 2004. - № 3 (40). - С. 4-8.

Рюгемер B. Новая техника - старое общество: Кремниевая долина / В. Рюгемер. - М. : Политиздат, 1989. -253 с.

Судзиловский Г.А. Сленг - что это такое? Англо-русский словарь военного сленга / Г.А. Судзиловский. - М. : Военниздат, 1973. - 182 с. 